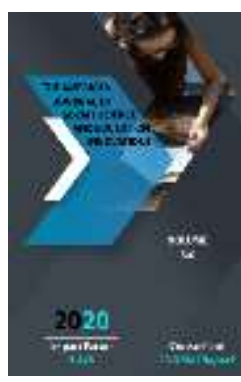

Journal Website: http://usajournalshub.c om/index,php/tajssei

Copyright: Original content from this work may be used under the terms of the creative commons attributes 4.0 licence.

\section{Methods Of Teaching Students To Do Sketches In Independent Learning}

\section{Botir Boltabaevich Baymetov}

Professor, Chirchik State Pedagogical Institute, Tashkent Region, Uzbekistan

Xusan Xolmuratovich Muratov

Associate Professor, Chirchik State Pedagogical Institute, Tashkent Region, Uzbekistan

\title{
ABSTRACT
}

The article discusses the key aspects that students need to pay attention to in the process of teaching independent work. Improving the methodology of drawing in the development of students' creative abilities and the use of theoretical laws of fine arts in the process of training, focuses on students gaining theoretical knowledge and practical skills in the process of developing the ability to see and describe the shape of the body from a distance.

\section{KEYWORDS}

Fine art, sketch painting, drawing, nature, artistic creation, imagination, form, rhythm.

\section{INTRODUCTION}

Self-directed learning plays an important role in the professional training of future fine arts teachers in higher pedagogical education. This process allows students to develop the knowledge and skills acquired in the classroom, workshops in the process of independent learning. The most important of these is the process of making sketches from nature. 


\section{THE MAIN RESULTS AND FINDINGS}

In the educational process, the performance of sketches is carried out in stages, as in drawing continuous learning, using the image method "From the general to the particular and from the particular to the general", which is the basis of the fine arts.

The last step in generalizing the shape of the object being depicted is to add clarity and combine the relationship of light and shadow into a coherent whole, from assembling and merging the object on paper into one whole. That is, it is a combination of the depicted form and the space in which it is located.

Drawing a short sketch of nature with its distinctive features is mainly intended to develop the ability to see and comprehend quickly.

Observation, perception, and sketch playback often occur simultaneously. Therefore, it is not necessary to talk about generalization as a final stage of work on the sketch. The sketches allow us to identify six types of differentiation of the methods used in drawing.

1. Sketches that are performed directly from beginning to end, observing nature.

2. Sketches depicted in the combination method (first from nature, then without nature - by memory).

3. Sketches, which are made only from memory, that is, after some time after observation, when the ability to see in the mind is strengthened.

4. Sketches on perceptions related to the ability to revive perceptions of certain objects, living objects, and surrounding phenomena previously perceived in the human mind.

5. Sketches performed by a complex method, ie using all the above methods of work, including imaginary methods.

6. Imagination - drawing generalized sketches on the basis of vivid recollection of any creative idea or artistic image, theme, plot, etc.

The second, third, and fifth types of sketches are combined with one common feature, namely: with a mandatory symptom that occurs simultaneously with the sketch drawing or shortly before the sketch drawing (the end of which is no longer in nature, in memory or in the imagination) with a more superficial and rapid observation of nature.

If the execution time is not limited, then such a sketch drawn from nature can become a drawing line.

When performing a sketch, the state, quantity and complexity of the simultaneously depicted object (at rest or in motion) depend, in other words, on the content of the sketch itself, as well as on objective conditions encountered in practice.

One of these conditions is whether or not time is limited for nature observation and sketch execution. This in turn depends on the immobility of nature or the degree of excitation (speed of movement). In other words, the method of sketching is primarily influenced by two factors: time and the state of nature.

Drawing a sketch from observation of nature can be done from beginning to end only under one condition, that is, when nature is completely motionless. Such nature can be, first of all, an inanimate object (for example, works of art, sculptures, architectural structures, ornaments, vegetables, fruits, flowers, trees, rocks and some types of landscapes, as well as a light-skinned person standing in front of a special task). (Picture 1) 


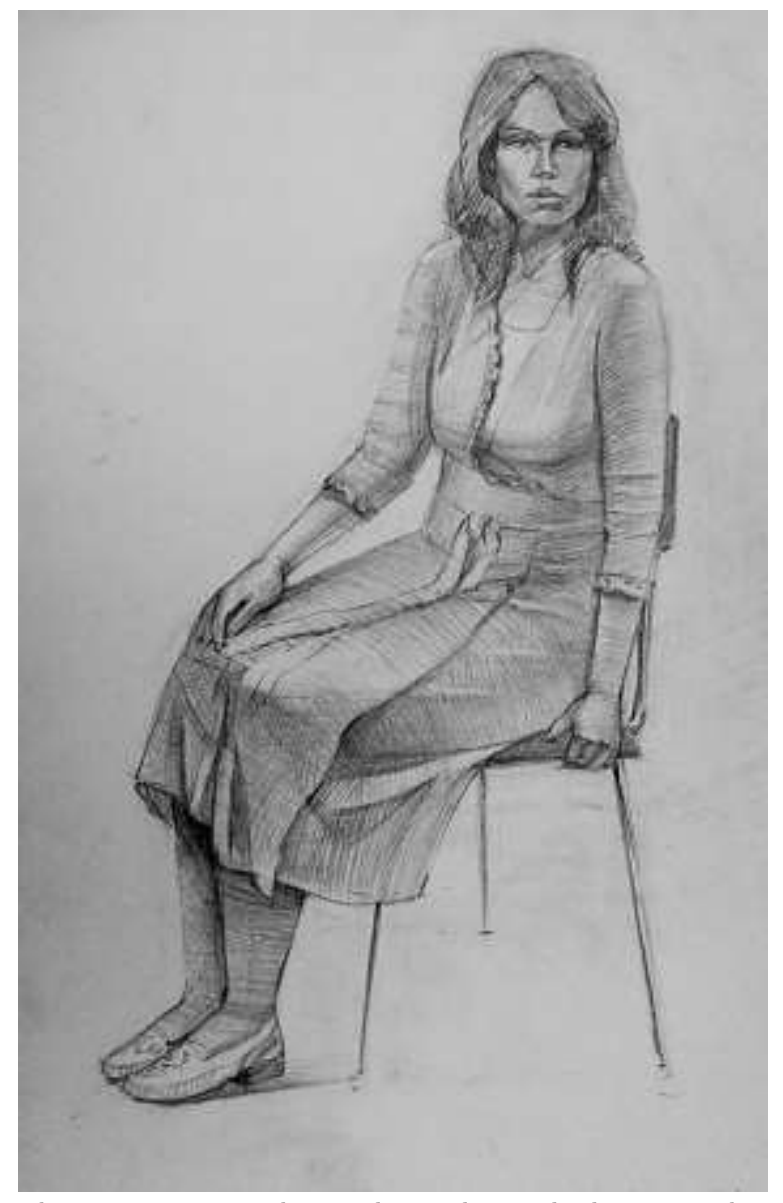

The artist works relatively calmly, as the purpose of the sketch is to reflect the general appearance of nature. If the goal has been achieved and nature is not yet moving, then it is possible to move from the sketch to the line (plate). It is even possible to make more detailed sketches of some pieces in addition to

the edge of the paper.

When sketching a landscape - you do not need to make sure that the weather or lighting conditions do not change, the wind can subside, a flat water surface can be agitated by waves, the sky can suddenly become covered with black clouds.

In nature, living nature does not stand in the same rhythm as in the artist's workshop or as a learning attribute in the classroom. It goes on in its life, and his natural, temporary immobility can be immediate, and sometimes unexpected, the opposite.

It should be noted that it is precisely such immobile conditions of a living model, namely, a calm, serene appearance, that are most valuable to the observer's observant eyes. On the contrary, a living model that stands specifically in the same state always loses its expressiveness, because in any case there is artificiality. In addition to, the look on your face will eventually get tired, which will affect your character.

That is why the artist must always be ready to accurately depict a living model in a sketch. It will be necessary to make efficient use of every minute, even every second, to observe and complete the sketch during the time available for work. It is no coincidence, therefore, that the word "sketch" has such meanings as "short", "very fast" "at a glance", "at lightning speed", and "in an instan".

The specific purpose of sketching is to instantly display the result of the observation on paper. True, if there is enough time, then it can not even be called a sketch.

In the audience, especially in the early stages of drawing, students always have ample time for both observation and drawing.

But working on a sketch outside of the auditorium, namely, both observing and drawing at the same time, can be abruptly interrupted. Sometimes the artist tries to achieve a goal faster, to immediately reflect the typical and characteristic features of nature. The tracking time coincides with the execution time. In such a case, with the perception of seeing nature, the execution is sharpened. That is, without distraction, without giving in to small, secondary details, one immediately tries to grasp the essential aspects of the subject, to use the simplest means to a minimum. If the student completes the sketches in color, it will be a great help for 
the students to successfully complete the continuing learning productions. (Picture 2 )

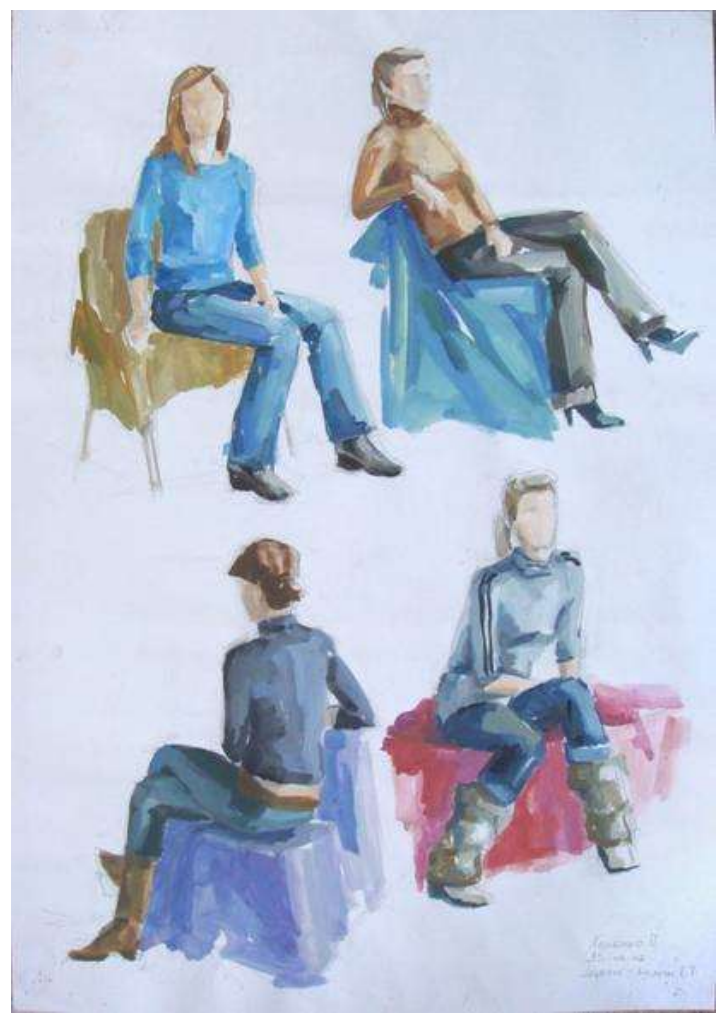

If the ability to see is strong, it is possible to achieve a very short and sometimes generalized depiction of forms that are imprinted in memory in a second. A sketch executed in this way is like a memory stamped on paper. Corrections and additions to such sketches are made only by repeating the action of the current athlete (almost the same action), by memorizing it again.

The need to work on a sketch, relying only on the ability to save it in visual memory, arises only in situations when external conditions allow observation. For example, a portrait of a passenger sitting in front of you on the subway looks like the character in the picture you are imagining, and the image you have been looking for for a long time comes out in front of you. It is impossible to draw it from nature, because it can take away its gaze, turn its head, or change its appearance, and so on.
You need to choose a way to solve the tasks you set yourself, so that you can use your vision: you observe, study, and try to remember the characteristic features of the character (especially the distinguishing features in it) without noticing your nature. For example, a passenger sitting in front of you on a city bus fell at his station. Then immediately, without delay, take your pocket album (otherwise it may fade from your memory) and draw a sketch from memory so that you remember the state of that passenger. (Picture 3)

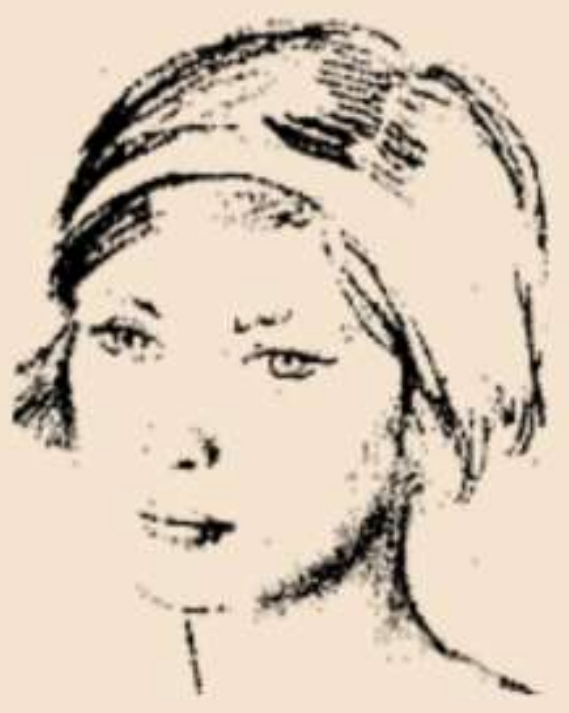

There are many such examples. But in order for an artist to develop visual memory, the person in motion needs to draw sketches, especially looking at a group of people whose character and speed of movement are different. For example, drawing sketches based on athletes involved in sports such as handball, football, athletics, gymnastics, volleyball will be a great factor in the development of skills such as plastic anatomy, linear constructive drawing.

\section{CONCLUSION}

In conclusion, it can be said that the nature of 
the image to be remembered as a result of observation and its imprinting in memory are influenced by many causes and circumstances. Especially in a partial case, a situation that is carefully observed in a schematic view of a line drawn from nature to paper and studied in the process of direct imagery is well preserved in memory. What is mechanically copied without analyzing the image is usually not stored in memory for long.

\section{REFERENCES}

1. Boltaboevich, B. B. (2020). Formation of the skills of portraying the future teacher of fine arts in pencil drawing. ACADEMICIA: An International Multidisciplinary Research Journal, 10(5), 1122-1127.

2. Baymetov, B. B., \& Muratov, K. K. (2020). Self Sketches as a Tool in the Professional Training of a Future Artist-Teacher. Solid State Technology, 224-231.

3. Baymetov, B. B. (2016). The history of the development of the fine arts of Uzbekistan. Science, education and culture, (1 (4)).

4. Baymetov, B. B., \& Sharipjonov, M. S. O. (2020). Development Of Students' Descriptive Competencies In Pencil Drawing Practice. The American Journal of Social Science and Education Innovations, 2(08), 261-267.

5. Boltabayevich, B. B., \& Shodievna, B. O. (2020). Individual Approach To The Formation Of Artistic And Creative Talents Of Students In Art Schools. The American Journal of Social Science and Education Innovations, 2(08), 637-642.

6. Boltabayevich, B. B, \& Pardaboy, K. (2020). SCIENTIFIC AND THEORETICAL ASPECTS OF THE FORMATION OF COMPOSITIONAL ABILITIES OF STUDENTS IN PAINTING CLASSES. European Journal of Research and Reflection in Educational Sciences Vol, 8(3).

7. Baimetov Botir Boltabaevich. Topical issues of training pedagogical personnel in the Republic of Uzbekistan. International scientific journal "BULLETIN OF SCIENCE" 2020/10. Volume 1.10 (31). Pages 5-9.

8. Boltaboevich, B. B., \& Ogiloy, K. (2008). MASTER OF HISTORICAL PORTRAIT GENRE, A TEACHER WHO CREATED A SCHOOL IN THE FIELD OF FINE ARTS PEOPLE'S ARTIST OF UZBEKISTAN PROFESSOR MALIK NABIEV (1906-2008).

9. Sultanov Kh.E. Innovation technology clusters use of technology in illustration / International Journal of Psychosocial Rehabilitation, Vol. 24, Issue 04, 2020: ISSN: 1475-7192. P. 3871-3879;

10. Sultanov Kh.E., Sobirov S.T., Исматов У.Ш. Illustration and the Influence of Illustrator on Children's Understanding of Fairy Tales and Works of Art in Books / International Journal of Psychosocial Rehabilitation, Vol. 24, Issue 05, 2020 ISSN: 1475-7193// p.35263533;

11. Boltabaevich Botir Baymetov. San'atshunoslik fakultyetlarida talabalarga qalamtasvir mashg'ulotlarini o'tishning nazariy asoslari. Materials of the Science and Education conference. 2020/5. Volume 2. Number No. 3. Pages-406-409.

12. Baymetov, B. B., Sobirov, S. T., \& Ismatov, U.Sh. (2019). PROBLEMS OF PROFESSIONAL AND PEDAGOGICAL TRAINING OF FINE ART TEACHERS. Bulletin of Science, 1 (7), 63-66.

13. Baymetov Botir Boltaboevich. Tasviry sanatdan blazhak rassom-kituvchilarni kasbiy tayyorlashda composition fanning nazariasi va methodikasi. Science and education journal. 2020/4. P. 461-467

14. Baymetov, B. B. (2020). PEDAGOGY OLIY TALIM MUASSASALARID TALABALARGA COMPOSITION FANINI ЎҚITISHNING NAZARIYASI VA AMALIYOTI. Science and Education, 1 (7).

15. Baymetov, B. B., Sultanov, H. E., \& Muratov, H. H. (2019). PSYCHOLOGICAL BASIS OF ACTIVATION OF CREATIVE ABILITIES OF STUDENTS IN THE PROCESS OF PRACTICAL EXERCISES. Bulletin of Science, 1 (7), 67-71. 
The American Journal of Social Science and Education Innovations (ISSN - 2689-100x)

Published: December 05, 2020 | Pages: 8-13

Doi: https://doi.org/10.37547/tajssei/Volume02Issue12-03

16. Boltabaevich Botir Baymetov.

Kaykaltaroshlik VA plastic anatomy. ўқuv Ilanma. Iқthisod-moliya. 2007yil.

17. Baymetov, B. B., Sultanov, Kh.E., Muratov, Kh.Kh., \& Sabirov, S.T. (2018). SCIENTIFIC AND THEORETICAL ASPECTS OF FORMATION OF COMPOSITIONAL ABILITIES AT STUDENTS IN PAINTING. In Modern Scientific Thought (pp. 83-94).

18. Baymetov, B. B., \& Talipov, N. Kh. (2016). METHODOLOGICAL SEQUENCE OF WORKING ON A PAINTING PORTRAIT IN A PEDAGOGICAL UNIVERSITY. Scientific discussion: issues of pedagogy and psychology, (4-1), 46-50.

19. Baymetov, B. B. (2020). Development Of The Ability To See And Represent The Form Remotely In The Process of Teaching Students To Portray A Creature In Higher Pedagogical Education. The American Journal of Applied Sciences, 2 (10), 154-159. 